\title{
Research Paper \\ Attitudes Toward Caring of the Elderly From the Perspective of Nursing and Midwifery Stu- dents in Kermanshah Province in 2015
}

\author{
Mohammad Mehdi Mohammadi ${ }^{1},{ }^{*}$ Masoumeh Esmaeilivand ${ }^{1}$
}

1. Department of Nursing, School of Nursing and Midwifery, Kermanshah University of Medical Sciences, Kermanshah, Iran

\begin{tabular}{l|l}
$\begin{array}{c}\text { Use yur devic to scan } \\
\text { and read the article online }\end{array}$ \\
Citation: Mohammadi MM, Esmaeilivand M. [Attitudes Toward Caring of the Elderly From the Perspective of Nursing and \\
Midwifery Students in Kermanshah Province in 2015 (Persian)]. Iranian Journal of Ageing. 2017; 11(4):476-483. http://dx.doi. \\
org/10.21859/sija-1104476 \\
doi: $:$ http://dx.doi.org/10.21859/sija-1104476
\end{tabular}

Received: 01 Jun. 2016 Accepted: 25 Sep. 2016

Keywords: Attitude, Elderly, Nursing, Care

\section{ABSTRACT}

Objectives Attitudes of health care providers towards patients can be an important underlying factor for providing efficient and effective care. Positive attitude of the nurses towards the patients coupled with more motivation and determination can be a mantra to better clinical services. The present study was conducted to determine the attitude of nursing students in relation to the care of the elderly.

Methods \& Materials This study is a descriptive study conducted on 211 students in Nursing and Midwifery, in Kermanshah Province, Iran in 2015. Data collection tool was a questionnaire consisting of 21 questions. Data analysis, including independent t test was done using SPSS 22.

Results The mean (SD) age of the participating nursing students was 97.5 (63.72) and nurse practitioners 27.7 (6.74) years. There was a statistically significant difference $(P<0.05)$. The majority of trainees $(8.89 \%)$ and nurse practitioners (3.81\%) had moderate approach to the care of the elderly. Items of ((nursing of the elderly is a waste of time because they have reached the end of his life)) from the perspective of Trainees $57.0 \pm 67.4$ and nurse practitioners $47.0 \pm 73.4$ had the highest average among the items that there was no significant difference between the two averages $(P>0.05)$.

Conclusion Although the majority of students have average attitude (not good) toward the elderly, it is felt that more specialized training is needed to improve knowledge and attitudes of aging. Considering that the nurse practitioners had a more positive attitude, teaching them is effective to create a positive attitude.

\section{* Corresponding Author:}

Masoumeh Esmaeilivand, MSc.

Address: Department of Nursing, School of Nursing and Midwifery, Kermanshah University of Medical Sciences, Kermanshah, Iran.

Tel: +98 (918) 3303646

E-mail: m_esmaeilivand@yahoo.com 


\title{
بررسى نگرش به مراقبت از سالمندان از ديدَّاه دانشجويان ثرستارى دانشكده يرستارى و مامايى

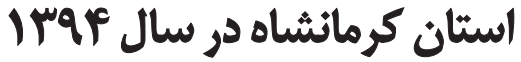

\author{
محمدمهدى محمدى'! "معصومه اسمعيلىوند' \\ 1- كروه هيرستارى، دانشكده هيرستارى و مامايى، دانشكاه علوم هزشكى كرمانشاه، كرمانشاه، ايران.
}

\begin{abstract}
(n)

\section{حكبد}

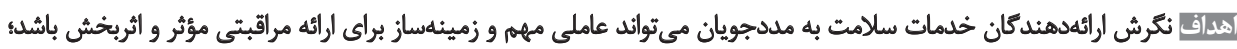

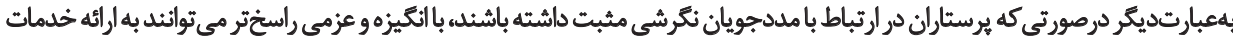

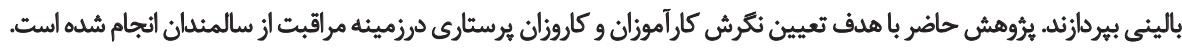

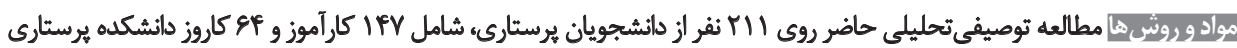

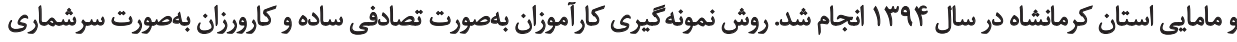

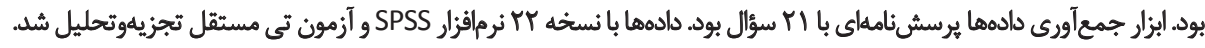

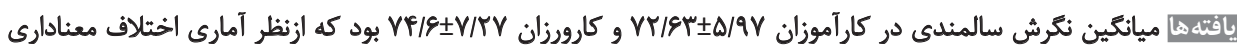

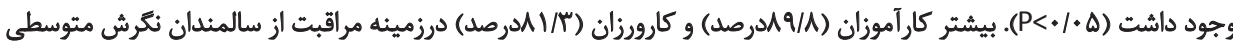

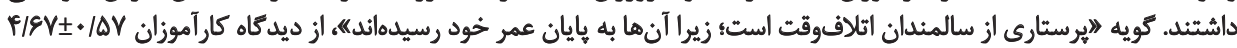

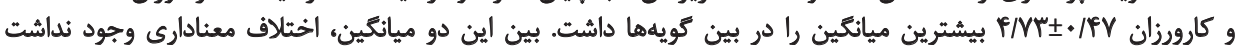
.$(P>\circ / \cdot \Delta)$

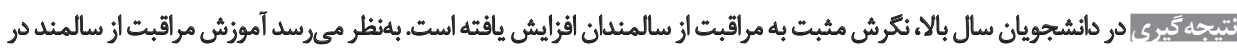

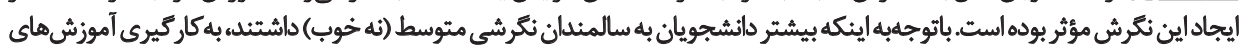

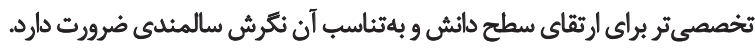

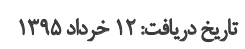

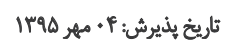

يديدالى جديد ثلقى مىشود كه بهادنبال عواملى تون كاهش ميزان

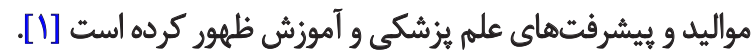

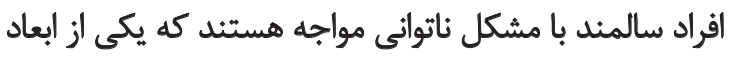

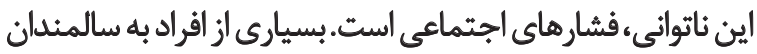

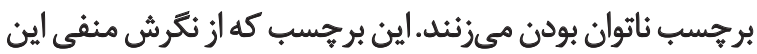

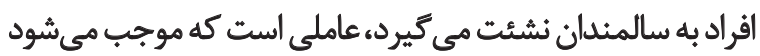

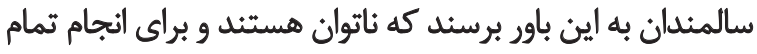

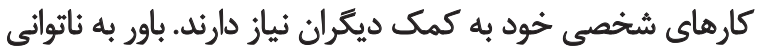

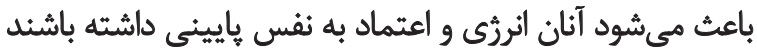

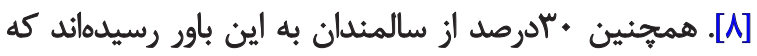

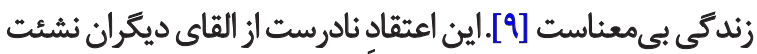

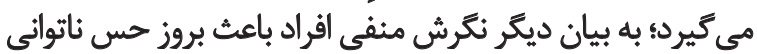

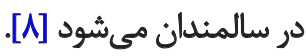

دراين ميان (بازئشستًى)، يكى از مسائلى است كه فرد سالمند
يديده سالمندى آخرين دوره از فرايند زندكى است كه همه

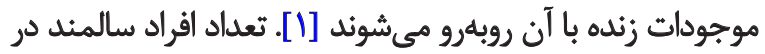

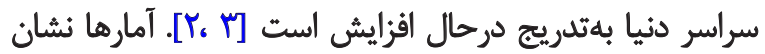

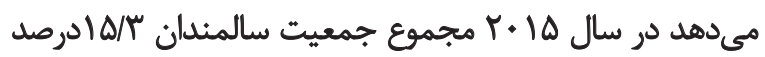

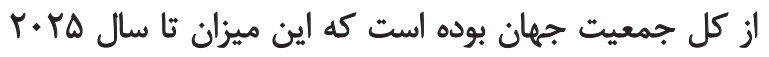

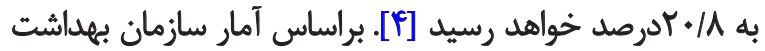

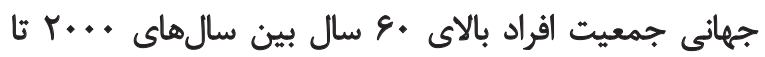

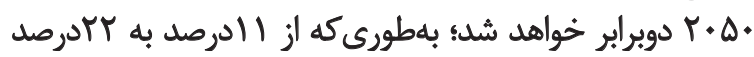

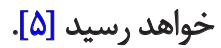

جمعيت سالمندان در بين ديكر كروههاى سنى سريعترين

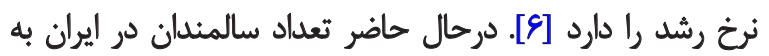

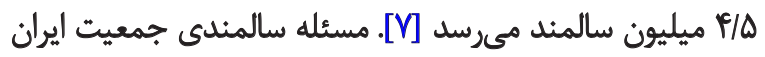

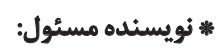

$$
\begin{aligned}
& \text { معصومه اسمعيلى نوند }
\end{aligned}
$$

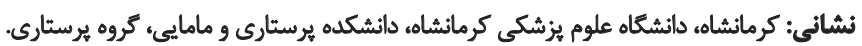

$$
\begin{aligned}
& \text { تلفن: }
\end{aligned}
$$

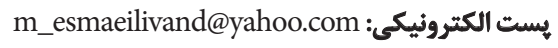




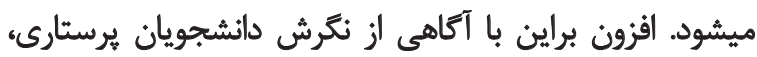

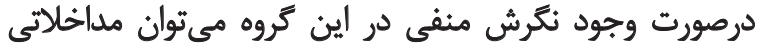

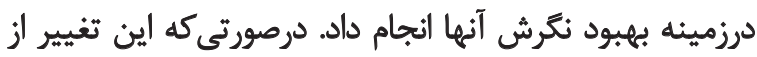

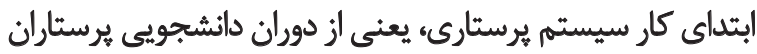

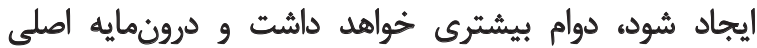

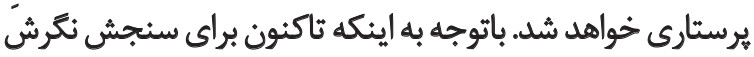

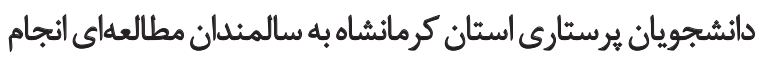

نشده است، ضرورت انجام مطالعه در اين زمينه احساس شدان بان

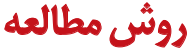

مطالعه حاضر، مطالعهاى توصيفىتحليلى است كه در سال

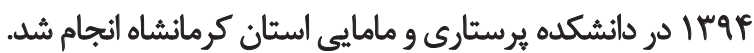

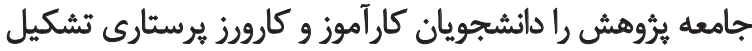

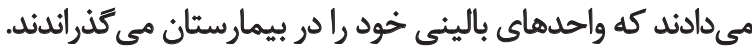

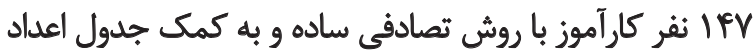

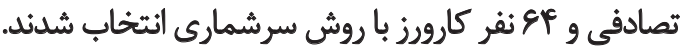
ابزار جمعآورى دادهها يرسشنامهاى شامل دو قسمت

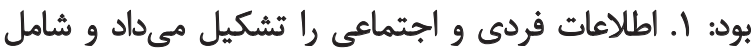

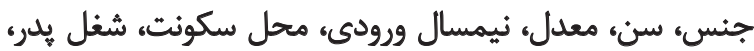

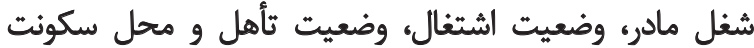

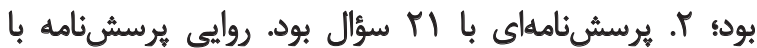

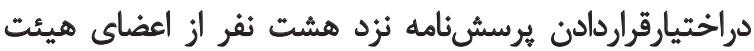

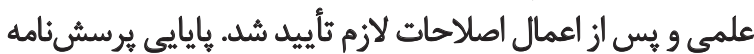

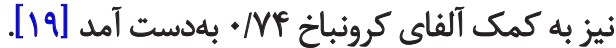

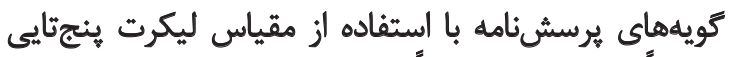

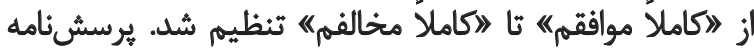

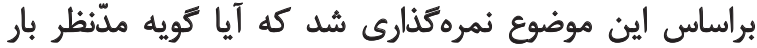

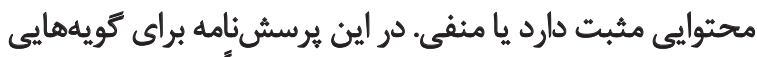

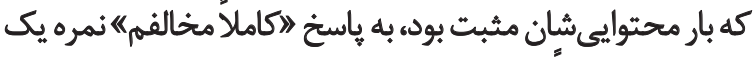

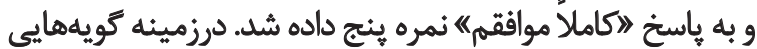

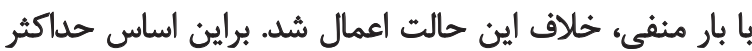

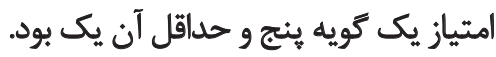

يس إز آن مجموع امتيازهاى برسشنامه، از جمع امتيازهاى

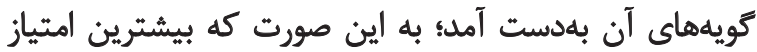

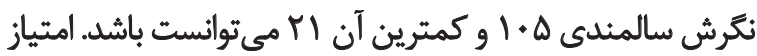

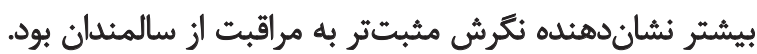

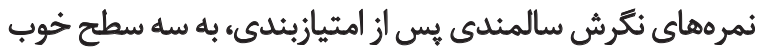

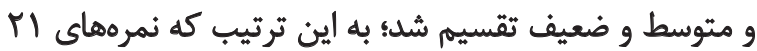

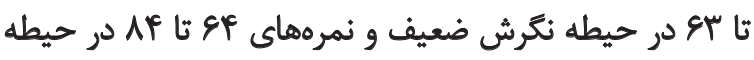

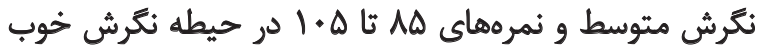

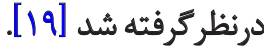
درابتدا هدف از مطالعه براى دانشجويان شرح داده شد و يساز
با آن مواجه مىشود. بازنشستكى موجب كاهش درآمد فرد

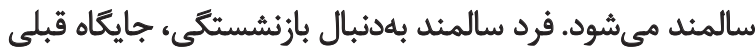

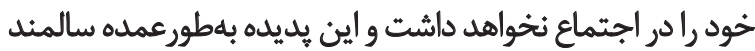

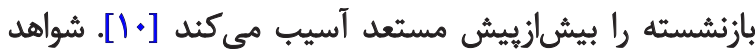
حاكى از آن است كه فشارهاى جسمى و وروائى و آسيبيديدي إنيرى

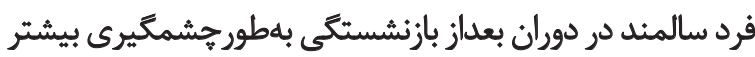

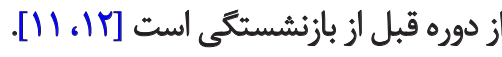

افزايش جمعيت سالمندان در جهان و ايران و نيز آسيبيذيرى برئي

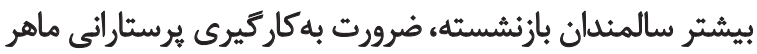

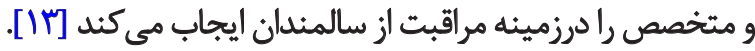

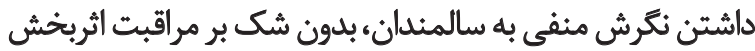

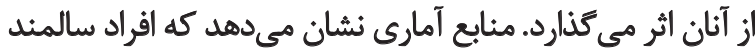

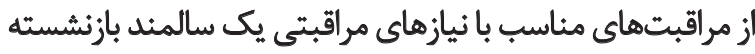

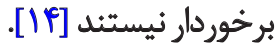

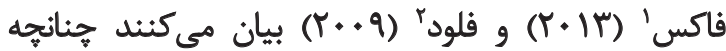

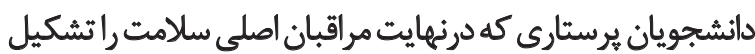

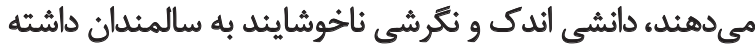

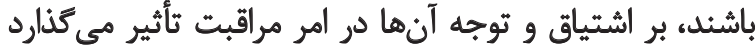

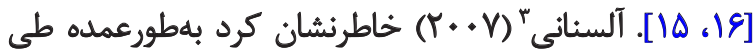

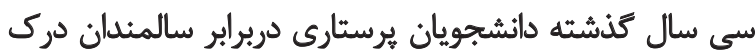

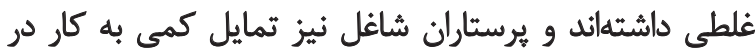

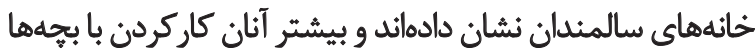

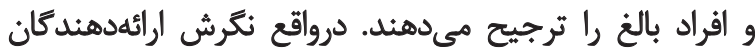

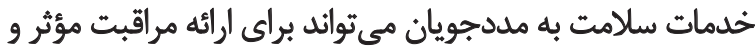

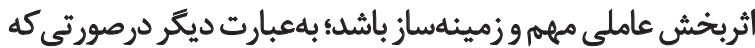

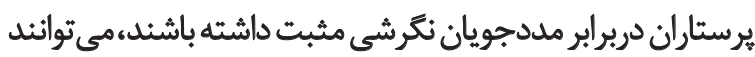

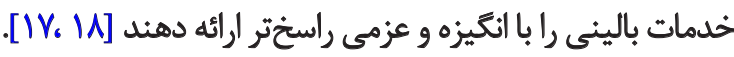
نتايج مطالعات نشان ميدهد بيشترين درخواست سالمندان

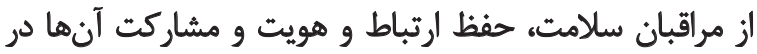

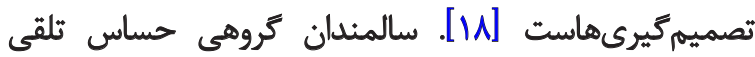

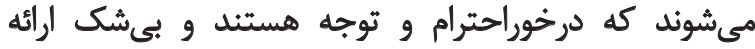

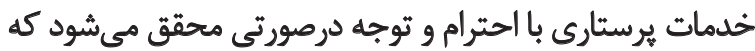

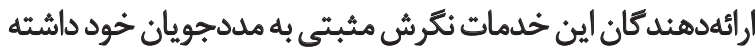

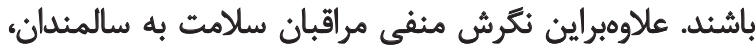
حس ناتوانى را به آنها القا مى كند. دانشجويان برستارى بهعنوان نهال اوليه نظام برستارى تلقى دئى

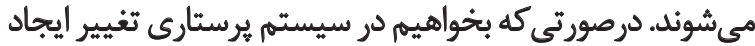

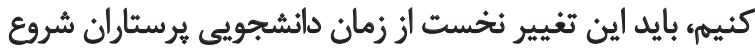

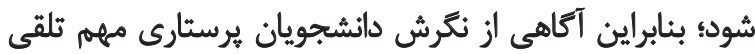


بود كه از نظر آمارى اختلاف معنادارى وجود داشت $(P>\odot \cdot \Delta)$

اطاطلاعات كلى درزميئه متغيرهاى جمعيتشناختى ديكر ماندا

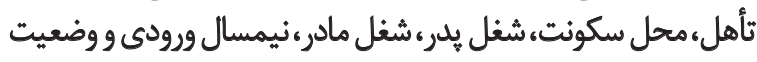

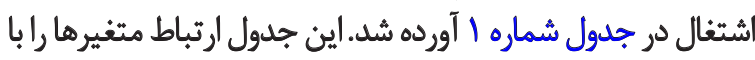

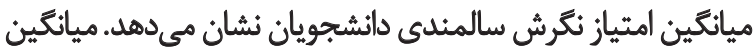

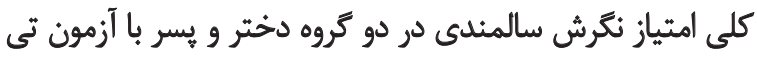

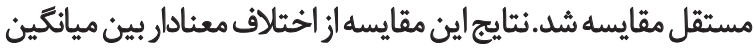

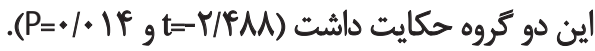

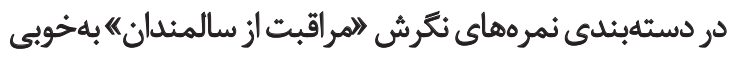

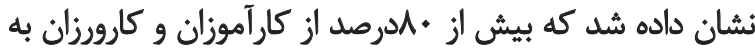

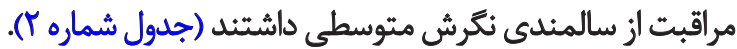
باتوجه به جدول شماره بـ از ديدكاه كارآموزان و كارورزان كويه

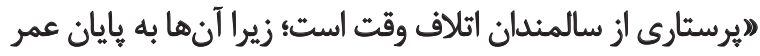

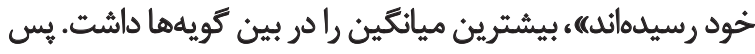

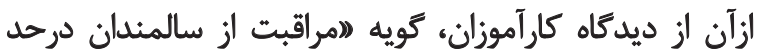

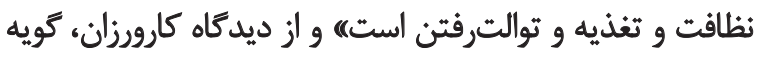

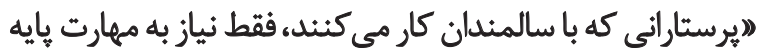

كسب رضايت آكاهانه، يرسشنامهها بين نمونهاي يروزهش

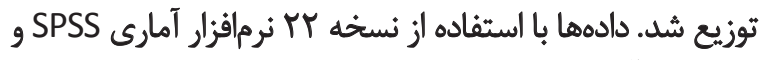

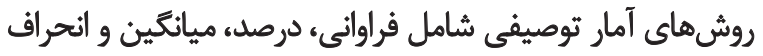

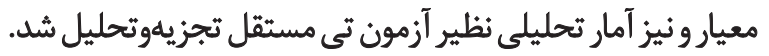

يافتهها

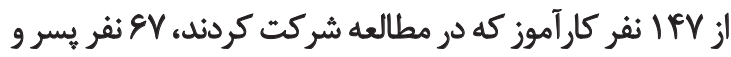

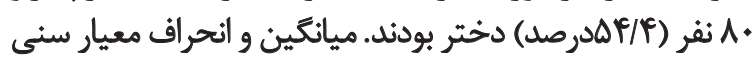

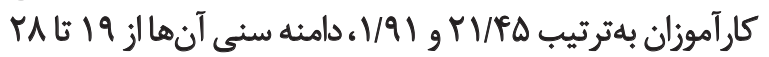

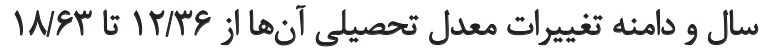

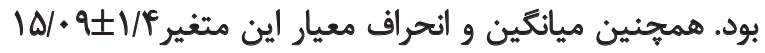

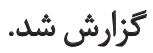

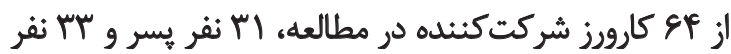

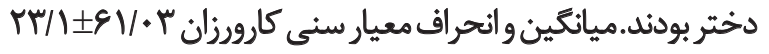

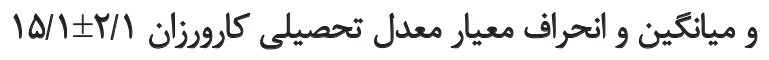

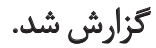

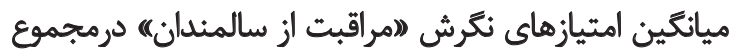
شا

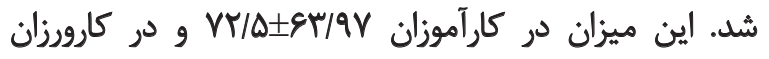

جدول ا. ارتباط برخى از متغيرهاى جمعيتشناختى با ميانكين كلى نكّرش مراقبت أز سالمثلدان.

\begin{tabular}{|c|c|c|c|c|c|c|c|}
\hline \multirow{2}{*}{ P-value } & \multirow{2}{*}{ ميانتين كلى } & \multicolumn{2}{|c|}{ كاروز } & \multicolumn{2}{|c|}{ كارآموز } & & \multirow{2}{*}{ متغيرها } \\
\hline & & مياتكين & فراوانى (درصد) & مياتئين & فراوانى (درصد) & & \\
\hline \multirow{2}{*}{$.1 \% 18$} & $n e / r e$ & $W / .8$ & $M(\Delta \backslash / P)$ & $n \pi /+1$ & $\Lambda \cdot(\Delta \varphi / \varphi)$ & دختر & \multirow{2}{*}{ جنسيت } \\
\hline & $n / .8$ & $r^{r}$ & $M($ IFNF) & $V T / \cdot \lambda$ & $\mathscr{R}(F \Delta / q)$ & بـر & \\
\hline \multirow{2}{*}{.1898} & $V \pi / 1 f$ & VE/RT & $\Delta r(A \backslash / Y)$ & $V T / \Delta q$ & $\mathbb{N} \cdot(\lambda V / \varepsilon)$ & مجرد & \multirow{2}{*}{ وضعيت تأهل } \\
\hline & 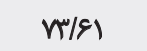 & $V \Delta / f^{\prime} I$ & $M(W A)$ & $V(A)$ & $W\left(W^{*}\right)$ & مثأهل & \\
\hline \multirow{2}{*}{ ATrA } & VT/eV & $n / 81$ & $r q(\Delta \& / M)$ & rile & $E \&(P F / q)$ & هنزل & \multirow{2}{*}{ محل سكونت } \\
\hline & $n / v a$ & $V \Delta / 19$ & $r A(P T / A)$ & $n / \% 1$ & $A)(\Delta \otimes /\rangle)$ & خوابكاه & \\
\hline \multirow{2}{*}{.$/ \pi n$} & $V T / 09$ & $V \% / .1$ & rAPRT/A) & VI/AT & $\Delta)(r+M)$ & دولتي & \multirow{2}{*}{ شغل يلر } \\
\hline & 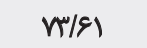 & $V \Delta / \cdot A$ & $r \&(\Delta F / \pi)$ & $n \pi / .9$ & $\vartheta(\varepsilon \Delta / \mu)$ & آزاد & \\
\hline \multirow{2}{*}{.$/ \cdot v^{c}$} & $\mathrm{n} / \mathrm{fr}$ & $n+/ \Delta$ & $N(I Y / \Delta)$ & $v \cdot 18$ & $r \cdot(r \cdot / r)$ & شاغل & \multirow{2}{*}{ شعل مادر } \\
\hline & $n / g r$ & $V F / g r$ & $\Delta \&(A V / \Delta)$ & $V \pi / 10$ & $11 Y(V q / 8)$ & خانهدار & \\
\hline \multirow{2}{*}{$.1 A$} & 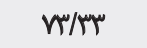 & $V \times / 91$ & $M c(\Delta H / M)$ & $V T / V A$ & $\mathrm{~V} q(\Delta H / V)$ & هير & \multirow{2}{*}{ ثيهمسال ورودى } \\
\hline & $V \pi / 1$ & $n+18$ & $r+(c \& / 9)$ & $V / F \Delta$ & SA(FE/T) & يجهن & \\
\hline \multirow{2}{*}{.$/ \Delta \Delta q$} & velir & $r / \Delta V$ & $V(1 . / 9)$ & nem & $\mathbb{N}(I T / Y)$ & بلي & \multirow{2}{*}{ شاغل } \\
\hline & $n / 11$ & $V \in / \Lambda \Delta$ & $\Delta \vee(\Lambda V /)$ & $V / M P$ & Irq(AV/A) & خير & \\
\hline
\end{tabular}


جدول Y. توزيع فراواني سطوح نكرش كارآهوزان و كارورزان به مراقبت از سالمندان.

\begin{tabular}{|c|c|c|c|c|}
\hline \multicolumn{4}{|c|}{$\log _{0} 5$} & \multirow{3}{*}{ دستهبندي نمره نئكرش } \\
\hline \multicolumn{2}{|c|}{ كاروز2:ان } & \multicolumn{2}{|c|}{ كارآموزان } & \\
\hline درصد & فراوانى & دوصد & فراوانى & \\
\hline$q / e$ & 8 & $\Delta / f^{e}$ & $A$ & حُوب \\
\hline 1)/r & $\Delta r$ & 19/1 & ITr & متوسط \\
\hline$q / f$ & $\varepsilon$ & $F / 1$ & $v$ & ضعيف \\
\hline $1 .$. & ge & $1 .$. & IFr & جمع كل \\
\hline
\end{tabular}

ك

جدول ب. مقايسه ميائكين نكرش به مراقبت از افراد سالمئد از ديدكاه كارآموزان و كارورزان.

\begin{tabular}{|c|c|c|c|c|c|c|}
\hline \multirow{2}{*}{ P-value } & \multicolumn{2}{|c|}{ كاروز } & \multicolumn{2}{|c|}{ كارأموز } & \multirow{2}{*}{ كويلها } & \multirow{2}{*}{ رديف } \\
\hline & انحرافمعيار & 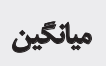 & اتحرافمعيار & مياتكين - - مين & & \\
\hline.$/ M V A$ & . prer & $r / M^{m}$ &.$/ \Delta \mathrm{V}$ & p/eV & 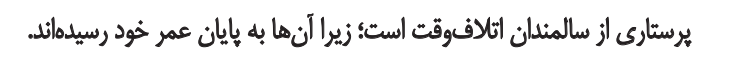 & 1 \\
\hline . MAH & $\cdot|A|$ & $r / t r$ &.$/ V$ & $F / \Delta A$ & مراقبت از سالمندان درحد نظافت و تثلذيه و توالترفتن است. & $r$ \\
\hline - / Far & . $/ 19$ & $f / \mu$ & . & $r / \mu \Lambda$ & مراقبت از بيماران سالمند بيش از مراقبت از ديكر بيماران به صبر و حوصله & $r$ \\
\hline$\cdot / M$ & $\cdot M^{e}$ & e/mq &.$|A|$ & $P / T V$ & هركونه سرمايهكذارى در مراقبت ازٔ سالمئدان نوعى اتلاف هزينه است. & p \\
\hline.$/ 419$ & .184 & $F / \Delta \mu^{\mu}$ & -NE & $r / F r$ & هيرستاراني كه با سالمندان كار مي كنند، فقط به مهارت بايه برستارى نياز & $\Delta$ \\
\hline.$/ 1 E N$ & $\mathbb{1} / \mathrm{M}$ & $r / \Delta \Delta$ &.$/ 98$ & $r / W$ & سالمندان تمايل دارئد با استفاده از سن خود از افراد جوان سوءاستفاده كنثد. & 8 \\
\hline 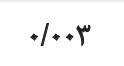 &.$/ N \Delta$ & $4 / 19$ &.$/ 94$ & r/ar & يبرستاران بهدليل كُندبودن سالمندان بايد زمان بيشترى را با آنان بكذرانند. & $r$ \\
\hline$+1+11$ & .194 & r/ar &.$/ 8 \lambda$ & $r / \pi 1$ & ايفاى نقش يوسثارى در مراقبت الز بيماران سالمند فراتر از مراقبت الز ديكران & $\Lambda$ \\
\hline$. / m+\lambda$ & $1 / 19$ & 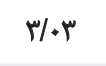 & M & $m / 19$ & صحبت با سالمندان خستهكننده و كسالت آور است. & 9 \\
\hline.$/ 1 \omega^{\circ}$ & .197 & r/ar & $\cdot M$ & $r / M$ & هر مراقبت از بيماران سالمند، به آنها الثكيزه داده مي شود تا استقالل يابند. & 1. \\
\hline.$/ 179$ & I/IV & r/ge & $V \cdot 8$ & $t / R F$ & وقتى كه هبرستار ان با حجم كاري سنكينى مشغول مراقبت هستند، بايد اولويت مراقبت & 11 \\
\hline$\cdot / 9 \cdot v$ &.$/ 94$ & $r / 81$ &.$/ 94$ & $r / \mathbb{T H}^{\prime}$ & بررستارانى كه با سالمثلدان كار مى كثند، معمولاً الكوهاى خوبى هستند. & ir \\
\hline $.1 .+1$ & $1 / \cdot 1$ & $r / \Delta r$ & $\cdot M$ & $r / 9 r$ & فقطط مربيائى كه درزهينه هر اقبت أز سالمندان مهارت دارئله بايد در اين باره & ir \\
\hline$\cdot / \pi r$ &.$/ 41$ & $r /$ & . $M E$ & $\mu / \mu$ & 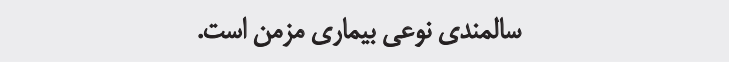 & if \\
\hline $.1 \cdot 1 f$ & $1 / \cdot r$ & $m / \%$ &.$/ M$ & $r / . r$ & سالمثلان همهترين هعضل در مراكز بهداشئيرومانى هستئد. & 10 \\
\hline$+1+\infty$ & $1 / r$ & 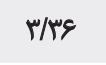 &.$/ 91$ & $r / \Lambda$ & بيشتر سالمنلان قادر به برقرارى كفتوكويى منطقى هستند. & 18 \\
\hline$\cdot M r \wedge$ & $M / M$ & $r / M$ & +11 & r/Ar & مراقبت از سالهندان خاص است و توجهات ويرٔهاى مى طلبد. & iv \\
\hline$+/ 1 r$ & $1 / \cdot 9$ & $r / Q V$ & $1 / \cdot 9$ & $r / 4$ & جيشتر مرييان علاقه به سالمندان را ارتقا مى دهئد. & in \\
\hline .1 .94 & $1 / \cdot 1$ & $r / .9$ & $\cdot / \wedge \Delta$ & t/AF & ييشتر يرستاران ترجيح ميدهند با جوانان صحبت كنند. & 19 \\
\hline.$/ M T \Delta$ & V/Tr & $r / \pi$ &.$/ 94$ & $r / M$ & بسيارى از برستاران براى كفتوكو با سالمنلان وقت مي كنارند. & r. \\
\hline $.1 . . r$ & $1 / r^{2}$ & $\Psi / K A$ & $\cdot / A F$ & $r / M$ & اطلاعات بيشتر هرييان درباره مراقبت از سالمنلان جديد نيست. & $m$ \\
\hline
\end{tabular}


خنثى در اين كروه سنى بدونشك بر سطح ارائه مراقبت به

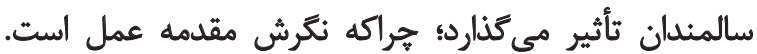

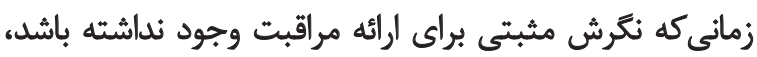

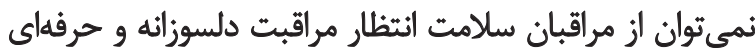

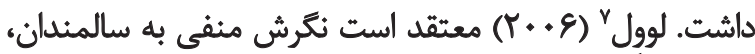

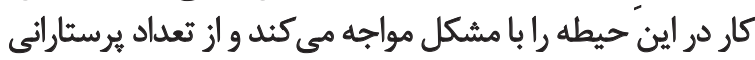

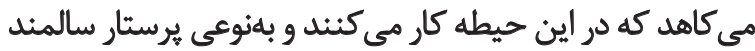

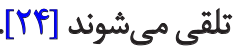

در هردو كروه كارآموز و كارورز كويه (ايرستارى از سالمندان

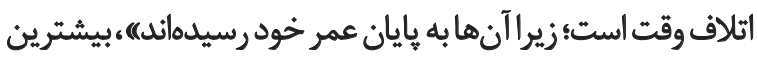

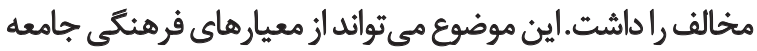

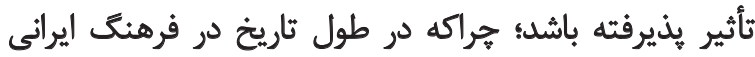

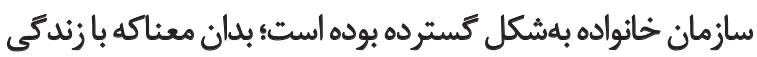

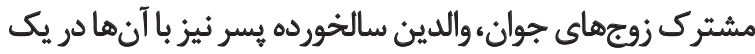

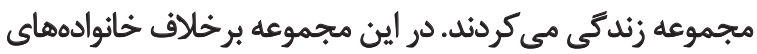

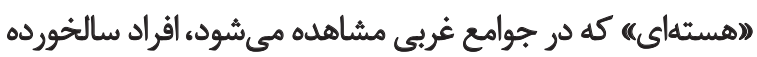

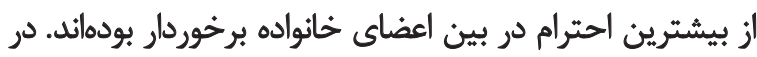

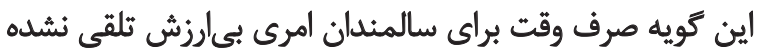
است و سالمندان را رازشمند دانستهاند.

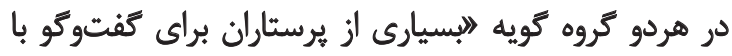

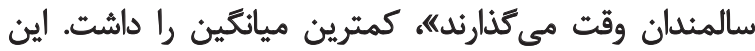

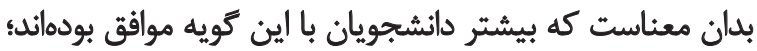

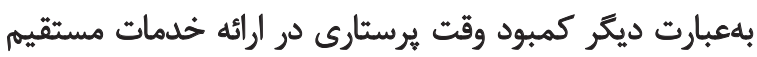

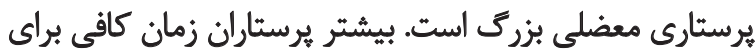

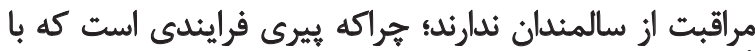

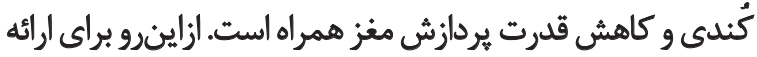

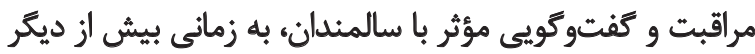

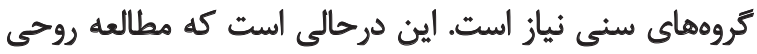

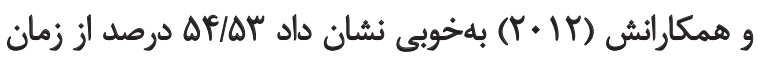

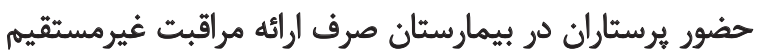

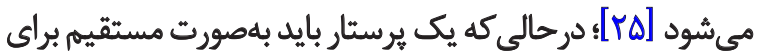

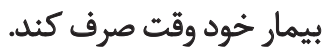

\section{نتيجليَيرىنهايى}

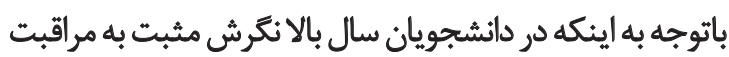

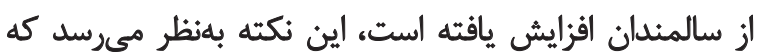

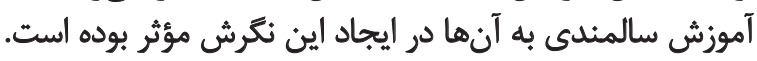

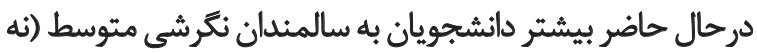

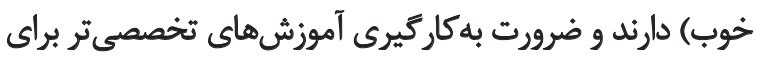

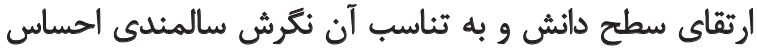

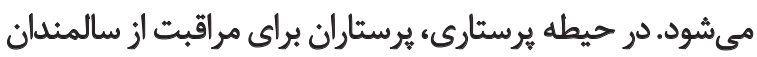

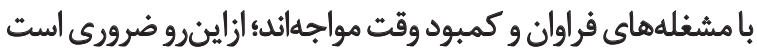

هرستارى دارند، نه بيشترا، بيشترين ميانكين را در بين كويهها

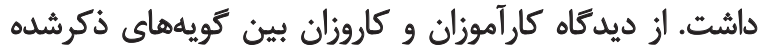

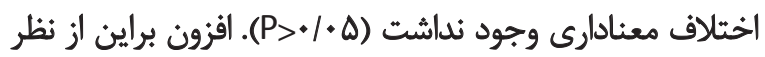

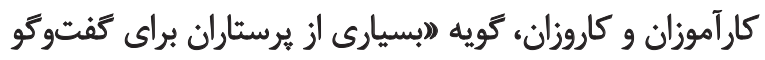

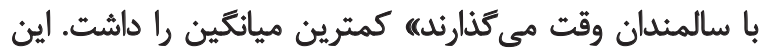

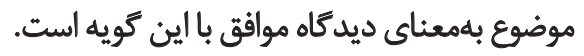

ث

كر مطالعه حاضر ميانكين نكرش سالمندى كارورزان درمقايسهبا

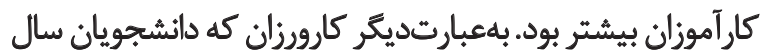

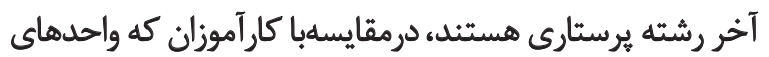

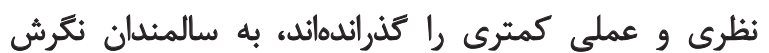

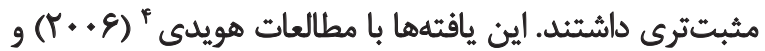

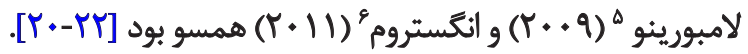
مطالعه حاضر نشان داد با بالارفتن ترم تحصيلى دانشجويان،

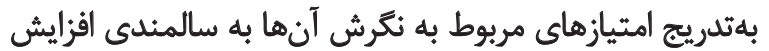

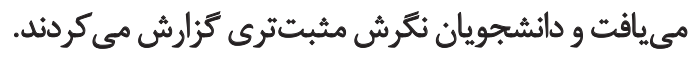

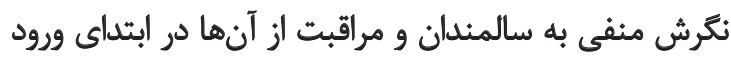

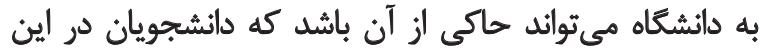

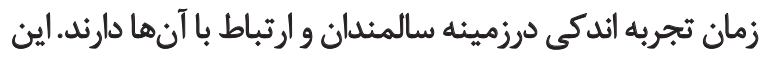

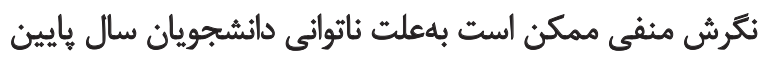

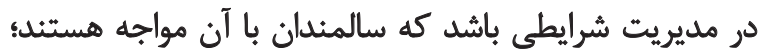

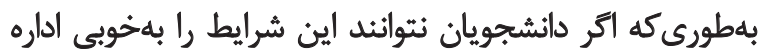

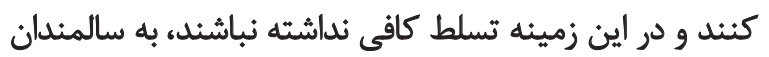

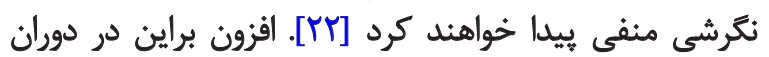

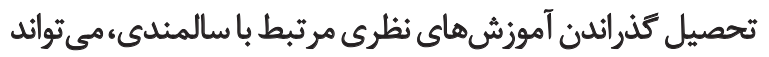

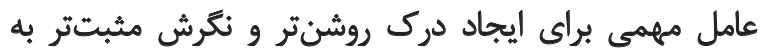

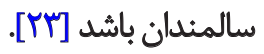

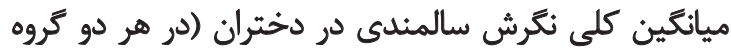

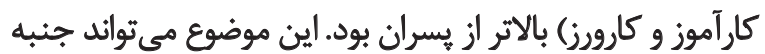

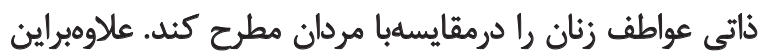

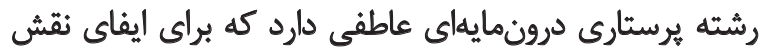

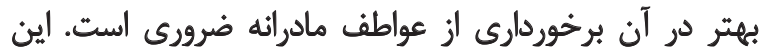

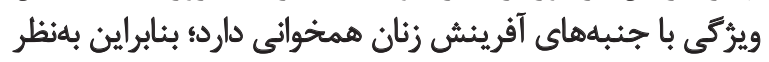

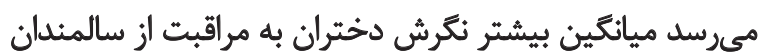

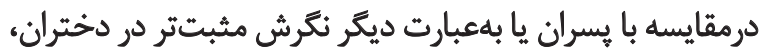
بهلت برخوردارى از ويرَكى عاطفى اين كروه است.

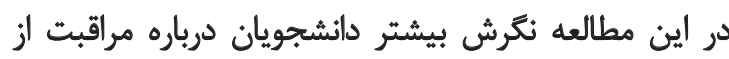

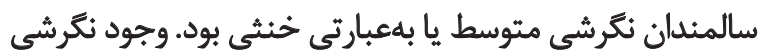

4. Hweidi

5. Lambrinou

6. Engström 


\section{References}

[1] Ghaysarian A. [Survey of social, economic dimensions of aging phenomenon in Iran (Persian)]. Journal of Population. 2009; 16(69-70):1-28

[2] Erdil F, Celik SS, Baybuga MS. Ageing and nursing services In: Troisi J, Kutsal YG, editors. Ageing in Turkey. Malta: Veritas Press; 2006.

[3] Tuohy D. Student nurse-older person communication. Nurse Education Today. 2003; 23(1):19-26. doi: 10.1016/s02606917(02)00160-0

[4] Celik SS, Kapucu S, Tuna Z, Akkus Y. Views and attitudes of nursing students towards ageing and older patients. Australian Journal of Advanced Nursing. 2010; 27(4):24-30.

[5] Eltantawy SH. Relation between nursing students' knowledge of aging and attitude towards elderly people and their will and intent to work with the elderly. Journal of Education \& Practice. 2013; 4(27):125-36.

[6] World Health Organization. 10 facts on ageing and the life course [Internet]. 2015 [Cited 2015 Sep 10]. Available from: http://www.who.int/features/factfiles/ageing/en

[7] Tajvar M. [Elderly health and review of aspects of their lives (Persian)]. Tehran: Nasle Farda Publications; 2004.

[8] Hatamipour KH, Zareie L. [Elderly health (Persian)]. Tehran: Boshra Publications; 2010.

[9] Malek Afzali H, Baradaran Eftekhary M, Hejazi F, Khojasteh T, Tabrizi R, Faridi T. [Social mobilization for health promotion in the elderly (Persian)]. Hakim. 2005; 9(4):1-7.

[10] Musaee M. [Social and emotional effects of retirement in faculty members; Case Study: University of Tehran (Persian)]. Human Sciences Modares. 2004; 8:157-179.

[11] Zhan Y, Wang M, Liu S, Shultz KS. Bridge employment and retirees health: A longitudinal investigation. Journal of Occupational Health Psychology. 2009; 14(4):374-389. doi: 10.1037/ a0015285

[12] Shultz KS, Wang M. The influence of specific physical health conditions on retirement decisions. International Journal of Aging and Human Development. 2007; 65(2):149-61. doi: 10.2190/ag.65.2.c

[13] Secrest J, Iorio DH, Martz W. The meaning of work for nursing assistants who stay in long-term care. Journal of Clinical Nursing. 2005; 14(2):90-97. doi: 10.1111/j.13652702.2005.01282.x

[14] McKinlay A, Cowan S. Student nurses' attitudes towards working with older patients. Journal of Advanced Nursing. 2003; 43(3):298-309. PMID: 12859789

[15] Fox JR. Educational strategies to promote professional nursing in long-term care: an integrative review. Journal of Gerontological Nursing. 2013; 39(1):52-60. PMID: 23413454

[16] Flood MT, Clark RB. Exploring knowledge and attitudes toward aging among nursing and non-nursing students. Educational Gerontology. 2009; 35(7):587-95. doi: $10.1080 / 03601270802605333$

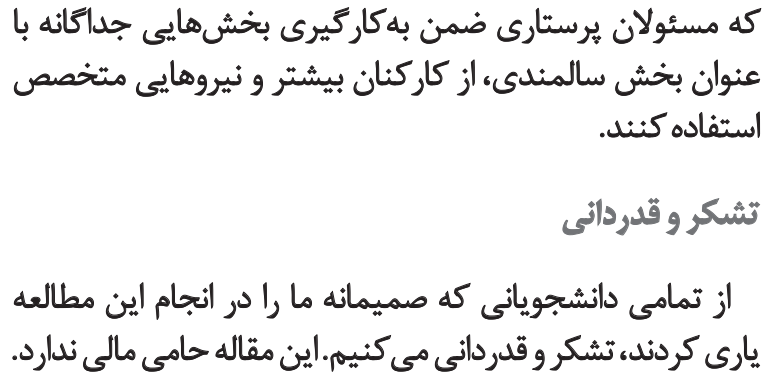


[17] Alsenany S. Student nurses' attitude and knowledge towards the care of older people in Saudi Arabia. British Society of Gerontology [Internet]. 2007 [Cited 2007 Oct 9]. Available from: http://www.britishgerontology.org/DB/ gr-editions-2/generations-review/student-nurses-attitudesand-knowledge-towards-the.html

[18] Bridges J, Flatley M, Meyer J. Older people's and relatives' experiences in acute care settings: systematic review and synthesis of qualitative studies. International Journal of Nursing Studies. 2010; 47(1):89-107. doi: 10.1016/j.jinurstu.2009.09.009

[19] Purfarzad Z, Ghamari Zare Z, Farmahini Farahani M, Ghorbani M. [Teachers and student nurses' attitudes towards caring for older adults in Arak, 2012 (Persian)]. Journal of Clinical Nursing \& Midwifery. 2014; 3(2):46-56.

[20] Hweidi IM, Al-Obeisat SM. Jordanian nursing students' attitudes toward the elderly. Nurse Education Today. 2006; 26(1):23-30. doi: 10.1016/j.nedt.2005.06.003

[21] Lambrinou E, Sourtzi P, Kalokerinou A, Lemonidou C. Attitudes and knowledge of the Greek nursing students towards older people. Nurse Education Today. 2009; 29(6):617-22. doi: 10.1016/j.nedt.2009.01.011

[22] Engström G, Fagerberg I. Attitudes towards older people among Swedish health care students and health care professionals working in elder care. Nursing Reports. 2011; 1(1):2-6. doi: 10.4081/nursrep.2011.e2

[23] Fagerberg I, Gilje F. A comparison of curricular approaches of care of the aged in Swedish and US nursing programs. Nurse Education in Practice. 2007; 7(6):358-64. doi: 10.1016/j. nepr.2006.11.007

[24] Lovell M. Caring for the elderly: changing perceptions and attitudes. Journal of Vascular Nursing. 2006; 24(1):22-26. doi: 10.1016/j.jvn.2005.11.001

[25] Rouhi Gh, Hosseini A, Rahmani Anaraki H, Mollaie E, Nasiri $\mathrm{H}$. [Distribution of workload and efficacy of nursing staff in internal medicine ward in a selected hospital of Golestan University of Medical Science (Persian)]. Journal of Research Development in Nursing \& Midwifery. 2012; 9(2):65-73. 